\title{
Rasismi ja seksismi pois koulutuksesta ja koulutuksella
}

\author{
$y$ \\ Human rights are women's rights and \\ women's rights are human rights. \\ - Hillary Clinton
}

SUOMESSA TASA-ARVO mielletään usein jo saavutetuksi ja siitä puhuminen koetaan kiusalliseksi. Suomi nähdään mielellään tasa-arvon edelläkävijänä, koska olimme Euroopan ensimmäinen ja maailman toinen maa, jossa naiset saivat äänioikeuden. Tasaarvon nykyinen tilanne ei kuitenkaan kestä kriittistä tarkastelua. Tasa-arvosaavutuksia on seurannut takaiskuja, ja nykyään Suomessa vallitsee naisvihamielinen ja antifeministinen ilmapiiri. Tämän voi huomata pintapuolisellakin nettisivujen selaamisella (ks. esim. Pullinen 2014). Feministiset tutkijat ja ajattelijat saavat tappo- ja raiskausuhkauksia, ja tulikivenkatkuisilla keskustelufoorumeilla syytetään kukkahattutätejä ja sosiaalitanttoja milloin mistäkin epäkohdasta, esimerkiksi koulutuksen ongelmista.

Tässä tekstissä käsittelen tasa-arvo-ongelmia ja feminismiä Suomessa ja ehdotan feministisen teorian ja käytännön ottamista mukaan opettajankoulutukseen.
NAINEN, EDELLEEN KAKKOSLUOKAN KANSALAINEN

Suomessa työmarkkinat ovat erittäin voimakkaasti jakautuneet sukupuolen mukaan. Naisten ja miesten palkkaerot ovat suuret, ja alle kouluikäisten lasten äitien työllisyys on Euroopan alimpia. Moni nainen tekee varsinaisen työpäivänsä pällle kotona toisen työpäivän kotitöiden ja lasten parissa. Sukupuoli- ja seksuaalivähemmistöillä ei edelleenkään ole samoja oikeuksia kuin muilla, ja maahanmuuttajien työllisyys on valtaväestöä huomattavasti alempi. (Julkunen 2010.) Naisiin ja tyttöihin kohdistuu paljon väkivaltaa ja seksuaalista häirintää ja hyväksikäyttöä, jota vähätellään ja neutraloidaan (esim. Aaltonen 2006). Työssä olevat maahanmuuttajat kohtaavat arjessaan paljon rasismia (esim. Ylä-Tuuhonen 2014). Ihmiskauppaan ei puututa aktiivisesti, eikä ihmiskaupan uhreihin suhtauduta vakavasti. Siksikö, että uhrit ovat 
ulkomaalaisia naisia, kysyy Eva Biaudet, Etyjin ihmiskaupan vastainen erityisedustaja.

Virallisesti naisten palkkatyö on normalisoitu ja nainenkin voi olla lastensa elättäjä, mutta edelleen naista pidetään toissijaisena elättäjänä. Äiti on yleensä se, joka jää kotiin lapsen kanssa ja jolla on huonompi palkka. Työn ei ajatella olevan naisille yhtä tärkeää kuin miehille, koska pätkätyöt ja osaaikaisuudet keskittyvät naisille. Se, että naiset tekevät osa-aikatyötä ja pätkätyötä, ei tarkoita, että he myös haluavat tällaisia työsuhteita. Työnantajalle jokainen nainen on potentiaalinen äitiys- ja hoitovapaan kustannuksien aiheuttaja, olipa tällä lapsia tai ei. Luulisi, että keski-ikäisiä ja vanhempia naisia uskallettaisiin palkata, mutta jostain syystä heidän on vaikea työllistyä - huolimatta kaikista työvoimapula- ja työurien pidentämispuheista. (Ks. esim. Filander 2006; Ruoholinna 2006.)

Richard Sennett (2002, 96-103) kirjoittaa ikäsyrjintää edistävistä asenteista: kokemusta ei arvosteta, ennakkoluuloilla legitimoidaan vanhimpien ulossaneeraukset. Vanhimmat työntekijät ovat yleensä kriittisimpiä, koska heillä on enemmän kokemusta ja itsevarmuutta. Ehkä juuri potentiaalinen kriittisyys on syy, miksi heitä vieroksutaan. Kenties ikä tuo naisten ulkonäköön ei-toivottavia piirteitä. Naisiin kohdistuu työelämässä ja muutenkin enemmän ulkonäköpaineita kuin miehiin, ja naisia esineellistetään mediassa ja etenkin mainonnassa (esim. Julkunen 2010).

Juha Siltala (2007) on todennut, että koulutus ei hyödytä naisia, kuten miehiä, vaikka juuri naisten koulutustaso on noussut. Aivan kuten koulumaailmassakin on piilo-opetussuunnitelma (Broady 1987), myös työelämässä ja jokaisella työpaikalla erikseen on niin sanottu piiloagenda, joukko kirjoittamattomia sääntöjä, jotka huomaa vasta, kun niitä on tullut rikkoneeksi. Niihin kuuluvat ikäsyrjintä ja lasikatto. Virallisestihan ketään ei saa syrjiä iän, sukupuolen, etnisyyden tai muun ammattitaitoon liittymättömän syyn takia, mutta miksi tiettyjen maahanmuuttajaryhmien on hyvin vaikeaa saada töitä? Miksi pätkätyöt keskittyvät naisille, miksi yli 55-vuotiaat ulos saneeratut eivät työllisty ja miksi naisvaltaistenkin alojen johtajista suurin osa on miehiä? Miksi akateemisesti koulutetut naiset ovat alemmassa työasemassa kuin opistotasoisen tutkinnon suorittaneet miehet? Miksi maahanmuuttajanaisia on enemmän työttöminä kuin maahanmuuttajamiehiä?

Edelleen on miehiä, joiden mielestä naiset ovat heitä alempana, olipa heidän ikänsä ja koulutustasonsa mikä hyvänsä, ja politiikassa naisia vähätellään ja heidän ulkonäöstään tehdään iso asia (esim. Talvitie 2013). Edelleen naisjohtajilta kysytään usein perheestä, vaikka se ei liittyisi aiheeseen, kun taas miesjohtajille perheen ja työn yhdistäminen on tabu (Virtanen 2013). Asenteiden muuttuminen kestää monesti sukupolvien ajan. Toimitusjohtaja Satu Huber sanoo huomanneensa selkeän sukupolvien välisen eron: "Hänen ikäluokkansa ja sitä vanhemmat miesjohtajat jättävät perheen mieluiten takaalalle, mutta häntä nuoremmat jakavat usein kotityöt tasapuolisesti ja myös puhuvat niistä." (Emt.)

Koulumaailmassa esiintyy seksuaalista häirintää ja naisopettajan valtaa saatetaan koetella, koska yhteiskunnassa on perinteisesti arvostettu maskuliinisuutta enemmän kuin feminiinisyyttä. (Palmu 2001, ks. myös Laine 1997 ja Lunabba 2013.) Olen huomannut työssäni, että aikuisopiskelijoista Lähi-idästä kotoisin olevat maahanmuuttajamiehet sekä työläismiehet kyseenalaistavat hanakimmin naisopettajan auktoriteettia. He saattavat suhtautua naisopettajaan halveksivasti ja esimerkiksi kieltäytyä katsomasta silmiin ja kättelemästä, vaikka se kuuluisi oppitunnin luonteeseen. Työväenluokkaiset keski-ikäiset naiset ovat oppineet vähättelemään itseään ja oppimismahdollisuuksiaan, ja aikuiskasvattaja saa motivoida heitä paljon ja huolehtia siitä, että miehet eivät dominoi luokkahuoneessa.

Suomessa syntyi naisliike yli sata vuotta sitten vaatimaan yleistä ja yhtäläistä äänioikeutta ja kansalaisoikeuksia naisille. Vaikka naiset ovat saaneet kansalaisoikeudet, naisliikettä tarvitaan edelleen, koska piilosyrjintä on yleistä. Toisaalta myös miehet, maahanmuuttajat ja seksuaalivähemmistöt kohtaavat arjessaan syrjintää. Niinpä naisliikkeestä on tullut yleinen tasa-arvoliike, joka nykyään ajaa mm. tasa-arvoista avioliittolakia ja järjestää naisille autonhuolto- ja itsepuolustuskursseja. (Naisasialiitto Unioni.) 


\section{PELOTTAVA F-SANA}

Suomessa feministi ja feminismi ovat rumia sanoja, ja puheenvuoro kuuluu aloittaa: "En ole feministi, mutta”. Feministien uskotaan haluavan alistaa miehet ja olevan naispuolisia sovinisteja. (ks. Julkunen 2010; Kotro \& Sepponen 2007.) Tasa-arvoa ilmeisesti hahmotetaan kateusmentaliteetin kautta: Jos joku saa jotain lisää, se on muilta pois. Tätä mentaliteettia kuvastaa Piia Elosen (2013) kolumni Helsingin Sanomien pääkirjoitussivulla. Koska Sdp:n kansanedustajista yli $60 \%$ on naisia ja puolueen kuudesta ministeristä neljä on naisia mutta samaan aikaan duunarimiesten työttömyys on lisääntynyt, tarvitaan naispoliitikkojen haastajiksi nimenomaan äijiä eikä vain miehiä. "Tyytymättömien mielestä toimihenkilönaisten kosiskelu on mennyt jo liian pitkälle eikä duunarimiehen etuja ajeta tarpeeksi pontevasti", kirjoittaa Elonen. Kirjoittaja asettaa siis vastakkain paitsi sukupuolet myös yhteiskuntaluokat. Myös Perussuomalaisten uudehko puoluesihteeri Riitta Slunga-Poutsalo kiirehti valintansa jälkeen vakuuttamaan, ettei ole feministi vaan pikemminkin sovinisti (Waris 2013). Naisen pitää siis olla hyvä jätkä ja sovinisti päästäkseen miesten kanssa samaan neuvottelupöytään. Naiset, jotka sanoutuvat irti feminismistä eivätkä halua tukea toisiaan vaan liittoutuvat mieluummin miesten kanssa, halveksivat omaa sukupuoltaan, toisinaan kenties tiedostamattaan (ks. Talvitie 2013).

Feministit kuvataan usein aggressiivisina, rumina, miehiä vihaavina kiihkoilevina lesboina (hooks 2007; Julkunen 2010). Toisaalta tämä on patriarkaalisen median jo 60-luvulta esittämää propagandaa, toisaalta kaikkien aatteiden edustajissa on yleensä liioittelijoita. Feminismiä kannattaisi lähestyä ilman ennakkoluuloja ja historialliset seikat huomioon ottaen. Tunnetun ja nykyään arvostetunkin feministin bell hooksin $(2007$; 2000) määritelmän mukaan feminismi on liike, joka pyrkii poistamaan seksismin sekä seksistisen hyväksikäytön ja sorron. Rasismi ja luokkaperustainen hyväksikäyttö kietoutuvat tiukasti seksismiin. Feminismi tulee siis nähdä yleisenä tasaarvoliikkeenä, joka pyrkii edistämään ihmisoikeuksien toteutumista - kuten Naisasialiitto Unioni määrittelee. Mainitussa järjestössä äänestettiin, pitäisikö miehiä alkaa hyväksyä jäseniksi. Myönteinen päätös olisi edistänyt asiaa paremmin kuin kielteinen, johon päädyttiin.

\section{VALKOINEN HETEROMIES, ENSISIJAINEN IHMINEN}

Sukupuolten välistä tasa-arvoa leimaa heteronormatiivisuus, joka ei ole sama asia kuin heteroseksuaalisuus. Heteronormatiivisuus sisältää kaikki ne oletukset, joita sukupuolista esitetään, esimerkiksi, että kaikkien pitäisi elää parisuhteessa ja hankkia lapsia. (esim. Lehtonen 2005.) Heteronormatiivisuus näkyy vaikkapa siinä, että jos nainen ja mies menevät autokorjaamoon, miestä saatetaan kohdella varsinaisena asiakkaana, vaikka hän olisi vain naisen seurana ja hänellä itsellään ei olisi autoa saati ajokorttia. Autoliikkeessä asioivaa naista saatetaan kohdella alentuvasti ja tökerösti. Vastaavasti sisustusliikkeessä naista kohdellaan ensisijaisena asiakkaana, ja ylipäänsä yhdessä liikkuvan miehen ja naisen kuvitellaan aina olevan pariskunta. Tästä on aiheutunut monenlaista tilannekomiikkaa, kun olen homoseksuaalisen ystäväni (mies) kanssa ollut liikkeellä. Olemme tahallamme myös huvitelleet heteronormatiivisuuden kustannuksella.

Naisvaltaisillakin aloilla miehet toimivat johtajina ja opillisina auktoriteetteina. Peter Jarvisin toimittamassa artikkelikokoelmassa ilmestyneessä Leicesterin (2001) artikkelissa kysytään, miksi naiset ovat aliedustettuina siinäkin kirjassa. Syyksi kirjoittaja arvelee koulutukselliset esteet. Tytöiltä ei ole odotettu saavutuksia, he ovat saaneet vähemmän huomiota opettajilta; vanhempien asenteet ja roolimallien puute. Edelleen yliopistoissa vallitsee miehinen ylivalta, ja naisten uskotaan olevan vähemmän kilpailuhenkisiä ja yksilöllisiä. (mt., 289-290.) On hyvä muistaa, että vielä sata vuotta sitten esimerkiksi kirjailija L. Onervan piti anoa vapautusta sukupuolestaan, jotta päs̈sisi opiskelemaan Helsingin yliopistoon. Siihen aikaan oli tavallista, että yliopiston (mies)professorit vähättelivät naisopiskelijoiden saavutuksia ja mitätöivät niitä. Naisen suorastaan odotettiin epäonnistuvan, olihan opiskelemaan pyrkinyt nainen luonnonvastainen. (Kortelainen 2006). 
Jane Thompsonin mukaan aikuiskoulutusorganisaatioita ja -politiikkaa luonnehtii seksismi. Koulutus on vahvasti sukupuolittunut ja uusintaa sukupuolistavia käytäntöjä. Näin on siitä huolimatta, että koulutukseen osallistuvista suurin osa on naisia. Vain naiset ovat tutkineet koulutuksen sukupuoliaspektia, mikä kertoo siitä, että se näyttäytyy miehille itsestään selvänä, kuten monille naisillekin. (Leicester 2001.)

bell hooks (2007) kritisoi yliopisto-opetusta valtarakenteiden pönkittämisestä sekä persoonallisuuden ja henkisen kasvun sivuuttamisesta. hooks vaatii vapauttavaa pedagogiikkaa, joka sallii myös opettajan kasvaa ihmisenä ja antaa jokaiselle äänen, vaikka se tuntuisi alkuun epämukavalta. On näennäistä tasa-arvoa sivuuttaa ihonväri ja sukupuoli puhuttaessa esimerkiksi mustasta naiskirjailijasta. Suomessa rasismia ei pidetä yleisesti ongelmana vaan se sivuutetaan vastaavanlaisilla argumenteilla kuin puheet naisten kokemasta epätasa-arvosta: Mitä maahanmuuttajat valittavat, monessa muussa maassahan asiat ovat huonommin? Olisivat kiitollisia, kun saivat tulla tänne. Tai sitten vedotaan maahanmuuttajien pieneen määrään ja aihe työnnetään marginaaliin. Maahanmuuttajat nähdään usein yhtenäisenä kategoriana, aivan kuten mustat tai naiset joissakin yhteyksissä.

Suomen kielessä ei ole sex/gender-dikotomiaa, joka on hyödyllinen näitä aiheita käsiteltäessä. Sukupuoli ei tietenkään ole pelkkä sosiaalinen kontruktio, eikä kukaan ole sellaista väittänytkään, jos tarkasteltavana on sex eli biologinen sukupuoli. Mutta gender sen sijaan on sosiaalinen konstruktio. Toisaalta biologinen sukupuolikaan ei ole yksiselitteinen asia, mistä on osoituksena intersukupuolisuus ja transsukupuolisuus.

\section{MIES KRIISISSÄ?}

Miehen asemasta ei ole ollut tarvetta käydä keskustelua, koska sitä on pidetty itsestään selvänä. Mies on ollut ihmisen normi ja nainen sen poikkeus. Vain poikkeuksista tarvitsee puhua. Vasta 1990-lu- vulla julkisuuteen tuli näkemyksiä, joiden mukaan mies on ajautunut vaikeuksiin muuttuvassa yhteiskunnassa. Perinteet eivät enää velvoita, kuten ennen, mutta mitä tehdä uudella vapaudella? Toisaalta vapaus voi olla näennäistäkin, onhan paljon piiloisia normeja. Mieheen kohdistuu ristiriitaisia odotuksia: pitäisi yhtä aikaa olla patriarkaalinen perheenpää ja moderni joustava mies. Juha Siltalan mukaan miehen vapaus onkin vain irrallisuutta. Miesten elämäkerroissa pärjäämisen eetos korostuu, eikä heikkoutta saa näyttää. Kulttuurimme keskeinen rakenne on häpeä. (Jokinen \& Saaristo 2002, 173-177.)

Raija Julkusen (2012) mukaan 1960-luvulla pidettiin suorastaan perverssinä ajatusta, että isien pitäisi hoitaa lapsia ja että he tarvitsisivat siihen lomaa. Isyysloma ilmestyi lakiin jo vuonna 1977, mutta vasta 2010-luvulla sitä on alettu pitää normaalina. Suomessa on pidetty itsestään selvänä, että on asevelvollisuus, joka koskee vain miehiä. Israelissa asevelvollisuus koskee kaikkia mutta kestää naisilla vuoden ja miehillä kaksi vuotta. Suomessa keskustellaan aika ajoin asevelvollisuudesta tasa-arvo-ongelmana, ja joskus olen nähnyt esitettävän, että sen voisi laajentaa yleiseen siviilipalveluun, jolloin naisten ja miesten pitäisi suorittaa joko siviilipalvelus esimerkiksi vanhustenhoidossa tai asepalvelus.

Onpa esseisti, suomentaja ja runoilija Timo Hännikäinen ehdottanut, että naisille pitäisi määrätä pakollinen palvelus valtion perustamissa bordelleissa, koska hänen ja muutaman muun "miesaktivistin" mielestä joidenkin miesten kärsimä seksinpuute on tasa-arvo-ongelma. Miesten oikeus seksiin ajaa siis naisten fyysisen itsemääräämisoikeuden ohi näiden herrojen ajatusmaailmassa. Miten Suomessa voi esiintyä näin räikeää naisvihaa, jos tämä on tasaarvon mallimaa?

Feminismiä ja naisten tasa-arvo-ongelmia mitätöidään usein vetoamalla miesten kokemaan todelliseen epätasa-arvoon. Miehet ovat yliedustettuina vangeissa, asunnottomissa, alkoholisteissa ja itse- 
murhan tekijöissä ja heidän elinajanodotteensa on lyhempi kuin naisten. Mutta onko tämä naisten ja feministien syytä? Eikö miesten tasa-arvoa voi ajaa samalla kuin naistenkin?

Jokisen (1999a) mukaan miehet kärsivät patriarkaalisessa yhteiskunnassa ja ovat sukupuoliroolien uhreja, kuten naisetkin. Miehet ovat yliedustettuina ongelmatapauksissa mutta myös etuoikeutetuissa ryhmissä, joilla on eniten valtaa ja omaisuutta. Miehiä ei sorreta sukupuolensa vuoksi, kuten naisia on sorret$\mathrm{tu}$ - ja sorretaan edelleen useimmissa maissa. Miehet kilpailevat keskenään, ja osa menestyy, osa ei. Kummallakin ryhmällä on naispuoliset tukijoukkonsa.

Kriittinen miestutkimus hyödyntää feministien kehittämää sukupuolen teoriaa. Se on osa feminististä projektia mutta oma alueensa, koska miehillä on erilainen suhde valtaan kuin naisilla. Yhtenä tavoitteena on tuottaa uusia tapoja puhua miehistä ja muuttaa vallitsevaa sukupuolijärjestelmää. (Jokinen 1999b.) Tasa-arvoa ei saavuteta vastakkainasettelulla vaan yhteistyöllä. Kuten hooks (2007) toteaa, miehiä ei pidä demonisoida eikä naisia ajatella uhreina, vaan tarvitaan maskuliinisuuden käsitys, jonka perustana on terve itsearvostus, ei heikompien alistaminen. hooksin (2000) mukaan ei ole olemassa merkittävää feminististä kirjallisuutta, jossa käsiteltäisiin poikia ja sitä, miten heitä autettaisiin muodostamaan identiteetti, joka ei perustu seksismiin. Antiseksistiset miehetkään eivät ole fokusoineet poikien kasvatukseen. Valitettavasti esiintyy paljon misogyynisiä käsityksiä, että äidit eivät voi kasvattaa kunnon poikia ja että pojat hyötyvät militaristisesta kasvatuksesta. Rakkautta ja tervettä itsetuntoa pojat kuitenkin tarvitsevat, ja lapset pitää kasvattaa ilman patriarkaalista alistamista, kasvattivat heitä sitten miehet tai naiset, homot tai heterot. (hooks 2000, 70-71, 77.)

\section{KIELI JA SUKUPUOLI}

Teksteihin sisältyy kielentutkijoiden mukaan tietty maailmankuva, myös kielenkäyttäjien itsensä huomaamatta. Kulttuurissa itsestään selvinä pidetyt hierarkisoinnit, esimerkiksi sukupuolihierarkiat, välittyvät usein teksteissä. Naisia on marginalisoitu kielellisin valinnoin. Näennäisen kielellisen sukupuolineutraaliuden takaa paljastuu sukupuolisesti jakautunut kulttuuri, jossa maskuliinisuus esitetään ensisijaisena. (Tainio 2002; Vuori 2002.) Kirjoittajan ja puhujan kannattaa miettiä kielellisiä valintojaan sukupuolen ja etnisyyden kannalta, jotta hän ei uusintaisi vallitsevia hierarkioita eikä aiheuttaisi tahtomattaan mielipahaa. Tainio (2002) suosittelee välttämään tiedemies- ja kielimies-tyyppisiä sanoja, koska ne voi korvata neutraaleilla sanoilla, kuten tutkija, tieteilijä. Nais-etuliite korostaa naisen poikkeuksellisuutta, mikä näkyy vaikkapa sanapareista naisjohtaja ja johtaja. Puhujan ja kirjoittajan kannattaa myös kiinnittää huomiota metaforien käyttöön, sillä ne ovat usein sukupuolittuneita ja voivat vahvistaa stereotyyppisiä käsityksiä.

Sukupuolieron voi Vuoren (2002) mukaan tuoda esiin kolmella tavalla. Vihjeenomainen sukupuoliero tarkoittaa kielellisiä keinoja, joiden avulla osoitetaan, että on olemassa kaksi sukupuolta mutta asiaan ei kiinnitetä sen enempää huomiota. Näitä kielellisiä keinoja ovat rinnastusten käyttö ja niiden vaihtelu, kumpi kategoria mainitaan ensin. Jyrkkä sukupuoliero tarkoittaa sukupuolten systemaattista esittämistä vastakkaisina. Tällöin naisista ja miehistä puhutaan eri tavoin ja heidät esitetään kahtena eri kategoriana eikä niinkään yksilöinä. Herkkä sukupuoliero tarkoittaa kantaaottavaa nimeämistä, reflektiivistä esittämistä, jossa vältetään kategorisointia. Feministitutkijoille herkkä sukupuoliero on luonteva valinta. Kaikki opettajat pitäisi herättää tiedostamaan kielen merkitys.

\section{SUKUPUOLISENSITIIVIÄ KASVATUSTA}

Ruotsissa tasa-arvokysymyksiin suhtaudutaan huomattavasti vakavammin kuin Suomessa, eikä siellä katsota tasa-arvoa saavutetuksi. Ruotsin yliopistoissa on oppiaine nimeltä genusforskning, ja kielessä on biologista sukupuolta tarkoittavan sanan kön lisäksi sosiaalista sukupuolta tarkoittava genus, joka vanhastaan tarkoittaa kielitieteessä kieliopillista sukua. Mainitun oppiaineen piirissä on todettu, että koululaitosta ja opettajankoulutusta leimaa vahva heteronormatiivisuus. Naisopettajat aliarvostavat itseään ja nostavat usein miesopettajat jalustalle. Naisenemmistöisessä työyhteisössä, kuten ala-asteella, miesopettajille annetaan helposti stereotyyp- 
pisten sukupuoliroolien mukaisia tehtäviä. Tyttöjä ja poikia kohdellaan eri tavalla. (Hultén 2011; Olofsson 2011a; Olofsson 2011b; Reuterstrand 2011 b.) Poikien heikosta koulumenestyksestä kannetaan huolta, vaikka pojat ja miehet menestyvät siitä huolimatta työelämässä tyttöjä ja naisia paremmin (Reuterstand 2011a). Suurimpia häviäjiä ovat koulussa huonosti menestyneet tytöt, mutta heidät on marginalisoitu koulupudokaskeskustelussa (Reuterstrand 2011b).

Vuorikosken (2007) tutkimus osoittaa, että opettajaidentiteetin rakentuminen on sukupuolittunutta. Opettajankoulutus ei rohkaise kiinnittämään huomiota sukupuoliproblematiikkaan. Tämä neutraalius on sukupuolisokeaa eikä anna tilaa epätasa-arvon esiin tuomiselle. Vuorikosken mukaan opettajankoulutuksen tulisi hyödyntää opiskelijoiden omia kokemuksia ja identiteetinrakennusta. (Mt., 217-218.) Opettajat toimivat myös heteronormatiivisesti ja epäpoliittisesti. Takavuosien taistolaisuuden tympäännyttämänä poliittisuutta saatetaan kaihtaa. Jos (aikuis)kasvatuksen halutaan olevan neutraalia ja epäpoliittista, se palvelee ainoastaan markkinavoimia ja globaalikapitalismia. Ne eivät kuitenkaan ole neutraaleja eivätkä välttämättömiä. Lasten sosiaalistaminen sukupuolijärjestelmään alkaa jo varhain, ja lastenvaate- ja leluteollisuus uusintavat stereotypioita.
Ruotsissa on Uumajan ja Göteborgin yliopistossa koulutettu erityisiä gender-pedagogeja, ja ensimmäiset valmistuivat vuonna 2005. Kuntia rohkaistiin palkkaamaan heitä. Opettajat ovat vastustaneet sitä voimakkaasti, sillä he eivät koe tarvitsevansa genderpedagogien apua työssään. Mentäessä pintaa syvemmälle huomataan kuitenkin helposti, että sukupuolisensitiiviselle pedagogiikalle on tarvetta. Mutta ei riitä, että sille annetaan pari tuntia projektiaikaa, vaan siitä pitäisi tehdä käytäntö. (Wigerfelt 2011.)

Seksismin ja rasismin kitkeminen vasta aikuiskoulutuksessa voi olla hankalaa, etenkin jos opettajat eivät ole tietoisia omista asenteistaan, kuten usein on asian laita (Hultén 2011). Siksi tarvitaan feminististä teoriaa ja käytäntöä kaikessa opettajankoulutuksessa varhaiskasvatuksesta aikuiskoulutukseen sekä etnografisia tutkimuksia muuallekin kuin peruskoulun yläluokille. Myös opettajien sukupuoliasenteita pitäisi tutkia. Vasta kun feminismi on kunnolla lyönyt itsensä läpi, voidaan odottaa tuloksia uusien opettajien kautta. Muutos kestänee useita sukupolvia.
Eva Sundgren
FM (viestintätieteet, suomen kieli),
KM (aikuiskasvatustiede, sosiologia)
lukion ja aikuislukion opettaja

\section{LÄHTEET}

Aaltonen, S. (2006). Tytöt, pojat ja sukupuolinen häirintä. Helsinki, Yliopistopaino.

Broady, D. (1987). Den dolda läroplanen. Stockholm, Symposion.

Elonen, P. (2013). Haastajaksi halutaan äijä. Helsingin Sanomat 17.9., A4.

Filander, K. (2006). Työ, koulutus ja katoavat ammattiidentiteetit. Teoksessa Mäkinen, Jarkko, Olkinuora, Erkki, Rinne, Risto \& Suikkanen, Asko (toim.). Elinkautisesta työstä elinikäiseen oppimiseen. Jyväskylä: PS-kustannus, 43-60.

hooks, b. (2007). Vapauttava kasvatus. Suom. Jyrki Vainonen. Helsinki, Kansanvalistusseura. hooks, b. (2000). Feminism is for everybody. Passionate politics. London, Pluto Press.

Hultén, E.-L. (2011). "Konstiga" lärare kan vidga elevernas vyer. Genus 2, 13-15.

Hännikäinen, T. (2009). Ilman. Turku: Savukeidas.

Jokinen, A. (1999a). Suomalainen miestutkimus ja - liike: muutoksen mahdollisuus. Teoksessa

Jokinen, A. (toim). Mies ja muutos. Kriittisen miestutkimuksen teemoja. Tampere University Press, 15-51.

Jokinen, A. (1999b). Tuntuu mieheltä. Teoksessa

Jokinen, A. (toim). Mies ja muutos. Kriittisen miestutkimuksen teemoja. Tampere University Press, $7-12$. 
Jokinen, K. \& Saaristo, K. (2002). Suomalainen yhteiskunta. Porvoo, WSOY.

Julkunen, R. (2012). Sosiologian perusopintojen kurssin Yhteiskunta luentotallenne. Jyväskylän yliopisto, Optima-oppimisympäristö.

Julkunen, R. 2010. Sukupuolen järjestykset ja tasa-arvon paradoksit. Tampere, Vastapaino.

Kortelainen, A. (2006). Naisen tie. L. Onervan kapina. Helsinki, Otava.

Kotro, A. \& Sepponen, H. T. (2007) (toim.). Mies vailla tasa-arvoa. Helsinki, Tammi.

Laine, K. (1997). Ameba pulpetissa. Koulun arkikulttuurin jännitteitä. Jyväskylä, Jyväskylän yliopisto.

Lehtonen, J. (2005). Heteroita oomme kaikki? Kasvatuksen heteroseksuaalinen normi. Teoksessa Mäkinen, J. \& Olkinuora, E. \& Rinne, R. \& Suikkanen, A. (toim.). Elinkautisesta työstä elinikäiseen oppimiseen. Jyväskylä, PS-kustannus, 155-174.

Leicester, M. (2001). Women in adult education second rate or second class? Teoksessa Jarvis, Peter (toim.). Twentieth century thinkers in adult and continuing education. Second edition. London, Kogan Page, 289-299.

Lunabba, H. (2013). När vuxna möter pojkar i skolan - insyn, inflytande och sociala relationer. Doktorsavhandling. Mathilda Wrede-institutets forskningar 1. Helsingfors, Helsingfors universitet.

Naisasialiitto Unioni. Verkkosivut. http://www.naisunioni.fi/. Luettu 2.10.2014.

Olofsson, C. (2011a). Förväntningar tynger manliga förskollärare. Genus 2, 16-17.

Olofsson, C. (2011b). Maskulint lärarideal hyllas i Klass 9A. Genus 2, 18-19.

Palmu, T. (2001). Kosketuspintoja sukupuoleen: opettajat, ruumiillisuus ja seksuaalisuus. Teoksessa Tolonen, T. (toim.). Suomalainen koulu ja kulttuuri. Tampere, Vastapaino, 181-202.

Pullinen, J. (2014). Naisvihan verkko. Helsingin Sanomat 4.9., A4.
Reuterstrand, S. (2011a). "Antiplugg" minskar pojkars chanser till jobb. Genus 2, 8-10.

Reuterstrand, S. (2011b). Flickor med dåliga betyg de största förlorarna. Genus 2, 11-12.

Ruoholinna, T. (2006). Ikääntyvänä muuttuvilla työmarkkinoilla. Teoksessa Mäkinen, Jarkko, Olkinuora, Erkki, Rinne, Risto \& Suikkanen, Asko (toim.). Elinkautisesta työstä elinikäiseen oppimiseen. Jyväskylä, PS-kustannus, 155-174.

Sennett, R. (2002). Työn uusi järjestys. Miten uusi kapitalismi kuluttaa ihmisen luonnetta. Suom. E. Kivinen ja D. Kivinen. Tampere, Vastapaino.

Siltala, J. (2007). Työelämän huonontumisen lyhyt historia. Helsinki: Otava.

Tainio, L. (2002). Tieteellisen tekstin sukupuolet. Teoksessa Kinnunen, M. \& Löytty, 0. (toim.) Tieteellinen kirjoittaminen. Tampere, Vastapaino, 51-63.

Talvitie, E. (2013). Keitäs tyttö kahvia. Naisia politiikan portailla. Helsinki, Wsoy.

Waris, O. (2013). Soinin uusi taistelupari: "Olen enemmänkin sovinisti". Iltalehti 29.6.2013. http:// www.iltalehti.fi/uutiset/2013062917207108_uu.shtml

Wigerfelt, C. (2011). Tiden för knapp för genuspedagogik. Genus 2, 21-23.

Vuori, J. (2002). Sukupuolen kirjoittaminen. Teoksessa Kinnunen, M. \& Löytty, O. (toim.) Tieteellinen kirjoittaminen. Tampere, Vastapaino, 95-107.

Virtanen, L. (2013). Perheestä puhuminen sallittu. Helsingin Sanomat 22.9., D4-D5.

Vuorikoski, M. (2007). Life history research challenges teacher professionalism. Teoksessa Rinne, R., Heikkinen, A. \& Salo, P. (eds.) Adult education Liberty, fraternity, equality? Nordic views on lifelong learning. Suomen kasvatustieteellinen seura, 203-220.

Ylä-Tuuhonen, M. (2014). Asiakkaat karttavat tummia kuljettajia. Helsingin Sanomat 27.8., A20. 